\title{
T-Cell Abnormalities in Common Variable Immunodeficiency
}

\author{
JON S. JAFFE, ELI EISENSTEIN, MICHAEL C. SNELLER, AND WARREN STROBER \\ Mucosal Immunity Section, Laboratory of Clinical Investigation, National Institute of Allergy and Infectious \\ Diseases, National Institutes of Health, Bethesda, Maryland 20892
}

\begin{abstract}
Common variable immunodeficiency (CVI) is a heterogeneous condition marked by a number of different immunologic defects. One group of patients, perhaps $60 \%$ of the CVI group as a whole, is characterized by T cells that produce reduced amounts of IL-2 (mRNA and protein product), IL-4, and IL-5 (mRNA) when stimulated with phytohemagglutinin. This defect does not extend to all lymphokines, however, because the cells produce normal amounts of interferon- $\gamma$ (mRNA and protein product) when exogenous IL-2 is present. Recently, we have reexamined the $T$ cell lymphokine production defect using a panoply of $T$-cell activation stimuli and have shown that the defect is a subtle one that depends on activation of the cell via the CD3-T-cell receptor complex. Because $T$ cells proliferate normally when stimulated via this receptor, this finding suggests the presence of a "downstream" defect, perhaps one involving the factors that are necessary for activation of lymphokine genes. A second form of CVI, in this case involving approximately $30 \%$ of the CVI group as a whole, is characterized by a reduced CD4/CD8 ratio and elevated numbers of CD8 $+\mathrm{T}$ cells bearing the CD57 marker. Although the CD4+ T cells in this patient group elaborate normal amounts of IL-2 under various activation conditions, their CD8+ $\mathrm{T}$ cells produce increased amounts of interferon- $\gamma$. Furthermore, the $\mathrm{CD} 8+\mathrm{T}$ cells in this case act as "suppressor" $T$ cells, which suppress IgG production but not IgM production of purified (normal) SAC+, IL-2-induced B cells. These "CD8 ${ }^{\text {hi" }}$ CVI patients display lymphocyte phenotype markers that are similar to those of patients with chronic viral infection; thus, it is possible that they have an immunodeficiency resulting from a subtle infection that results in the development of $T$ cells capable of down-regulating B-cell responses. Overall, these studies allow a better definition of CVI and suggest potential lymphokine-based therapies of selected patients. (Pediatr Res 33 (Suppl): S24-S28, 1993)
\end{abstract}

\section{Abbreviations}

CVI, common variable immunodeficiency

IFN- $\gamma$, interferon- $\gamma$

PHA, phytohemagglutinin

CVI is a heterogeneous group of disorders characterized by hypogammaglobulinemia and recurrent infection (1). In the 1970 s and 1980s, numerous in vitro studies of CVI patients' mononuclear cells were performed using increasingly purified cell populations and increasingly defined methods of cell stimu-

Correspondence: Warren Strober, M.D., Mucosal Immunity Section, Laboratory of Clinical Investigation, National Institute of Allergy and Infectious Diseases, National Institutes of Health, Bethesda, MD 20892. lation to characterize the cellular defect in this disease (2-6). A general result of these studies was that, whereas CVI $T$ cells provided normal help to (allogeneic) B cells in assays of in vitro Ig synthesis, CVI B cells could not be helped by (allogeneic) normal $T$ cells. In addition, whereas some patients manifested abnormally increased suppressor T-cell activity, the latter was usually associated with B cells that do not perform normally in vitro after enrichment and coculture with normal $\mathrm{T}$ cells. Overall, these findings led to the view that CVI is largely, if not totally, due to an abnormality of $\mathrm{B}$ cells. More recently, however, several studies have appeared that show that CVI T cells do not function in a completely normal fashion and that these patients' B cells do not function in a completely abnormal fashion $(2,7-10)$. In these studies, it was found that mitogen-induced T-cell proliferation and IL-2 production in the CVI patient population as a whole are reduced and that CVI patient $\mathrm{B}$ cells frequently produce respectable amounts of IgM (but not $\operatorname{IgG}$ or $\operatorname{IgA}$ ) when stimulated in vitro $(3,7,10-12)$. These studies reopened the question of whether $T$ cells in CVI patients are normal and set the stage for our own studies of CVI, which had, as a goal, the measurement of the capacity of CVI T cells to produce various lymphokines.

\section{PATIENTS WITH NORMAL T-CELL PHENOTYPES}

In our initial studies, we focused on the CVI patients with normal T-cell phenotypes, who constitute about two thirds of patients with CVI. In particular, we studied patients who exhibited normal numbers of CD4+ and CD8+ T cells as well as a normal proportion of CD45RA-bearing $T$ cells. This last point is important because it is now quite clear that CD45RA- and CD45RO-bearing $T$ cells (so-called naive and memory $T$ cells, respectively) have different lymphokine production profiles, so that a change in the CD45RA/RO ratio could be a relatively trivial cause of a lymphokine production abnormality (13). In addition, these patients had normal PHA-induced proliferation values, indicating that any lymphokine production defect, if present, could not be the result of an abnormality of $\mathrm{T}$-cell growth.

In a typical study, we determined the capacity of peripheral blood mononuclear cells (containing CD4+ and CD8+ T cells) stimulated by the T-cell mitogen PHA to produce IL-2, IL-4, IL5, IFN- $\gamma$, and IL-2R $\alpha$ mRNA using the RNA slot-blot technique. As shown in Figure 1, patient T cells produced about 10 to $40 \%$ as much IL-2 mRNA as normal $\mathrm{T}$ cells; in addition, they produced decreased amounts of IL-4 and IL-5 mRNA. The IL2 mRNA production deficiency was accompanied by an abnormality of IL-2 secretion as assessed by ELISA of IL-2 secretion into culture supernatants.

These findings contrasted somewhat with those relating to IL$2 \mathrm{R} \alpha$ and IFN- $\gamma$ mRNA production. First, T-cell IL-2R $\alpha$ production, as measured both by mRNA expression in slot blots and by cell surface expression (CD25), was completely normal. Second, whereas IFN- $\gamma$ mRNA production was normal at $6 \mathrm{~h}$ 


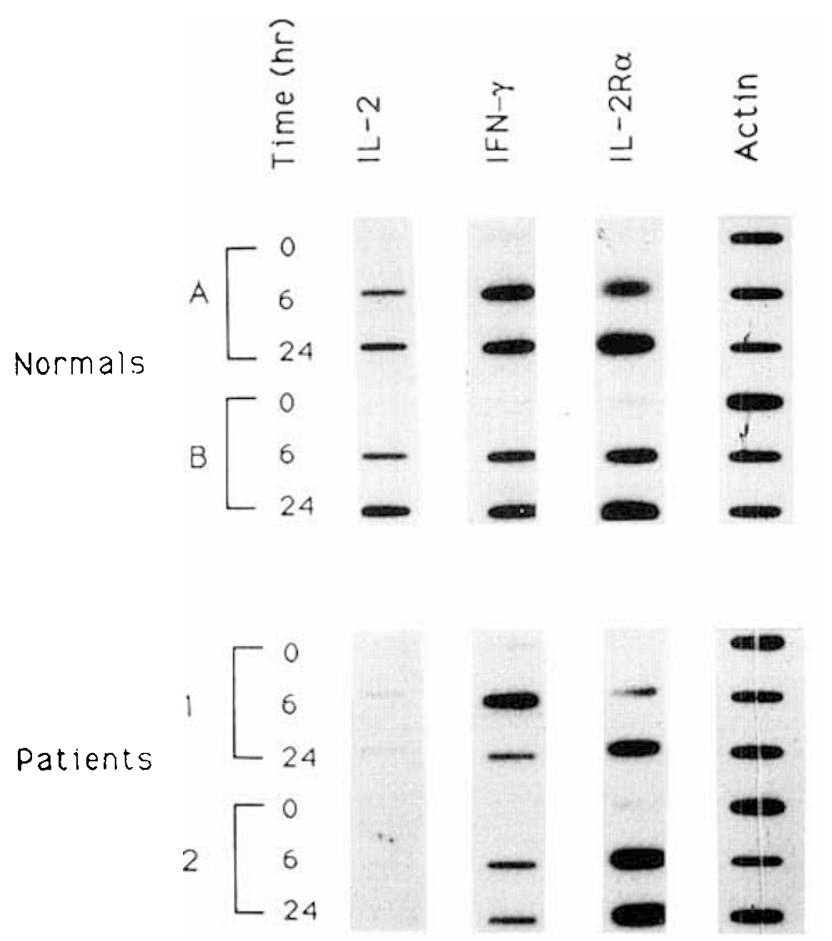

Fig. 1. Expression of IL-2, IFN- $\gamma$, IL-2R $\alpha$, and actin mRNA in two normal individuals $(A$ and $B$ ) and two patients with CVI ( 1 and 2$)$. Peripheral blood mononuclear cells were stimulated with PHA, and total cellular RNA was extracted at 0,6 , and $24 \mathrm{~h}$. One $\mu \mathrm{g}$ of RNA was then "slot blotted" onto nitrocellulose and sequentially hybridized with ${ }^{32} \mathrm{P}$ labeled human cDNA probes.

after PHA stimulation, it was abnormal at $24 \mathrm{~h}$ (Fig. 1). This pattern of abnormality suggested that the IFN $-\gamma$ production defect was secondary to the IL-2 production defect because it has been shown previously that IFN- $\gamma$ production is biphasic and that the second phase is IL-2 dependent $(14,15)$. To investigate this possibility, we measured IFN- $\gamma$ mRNA production of CVI cells that were stimulated in the presence and absence of exogenous recombinant IL-2. In these studies, we could show that both IFN- $\gamma$ mRNA and IFN- $\gamma$ protein production measured 24 $\mathrm{h}$ after cell stimulation are, in fact, normal when adequate IL-2 is added to the patient cell cultures.

The above-stated lymphokine abnormalities are quite obviously partial abnormalities that may have little or no physiologic significance. To investigate this question, we determined the capacity of supernatants from PHA-stimulated patient $T$ cells to support Ig production by SAC-activated normal B cells. We found, as shown in Figure 2, that PHA-stimulated CVI T cells give rise to supernatants that provide relatively poor help when compared with the help provided by supernatants derived from normal $\mathrm{T}$ cells; this suggests that the lymphokine production defect noted above can have consequences for B-cell differentiation under certain circumstances.

In more recent studies, we have investigated the capacity of highly purified CD4+ T cells, obtained with immunomagnetic bead technology, rather than whole peripheral blood leukocyte populations, to respond to particular T-cell stimuli. In these studies, we measured lymphokine mRNA production using a quantitative reverse transcriptase polymerase chain reaction technique and lymphokine protein secretion using ELISA methodology. We found again that most CVI patients with normal $T$ cell phenotypes produce less IL-2 mRNA and IL-2 protein than normal CD4+ $T$ cells. In addition, we showed that whereas stimulation of $\mathrm{T}$ cells with anti-CD3 antibody (i.e. stimulation of $T$ cells via the TCR-CD3 complex) led to reduced IL-2 production, stimulation with anti-CD3 plus a costimulatory antibody, anti-CD28, led to normal IL-2 production. This finding

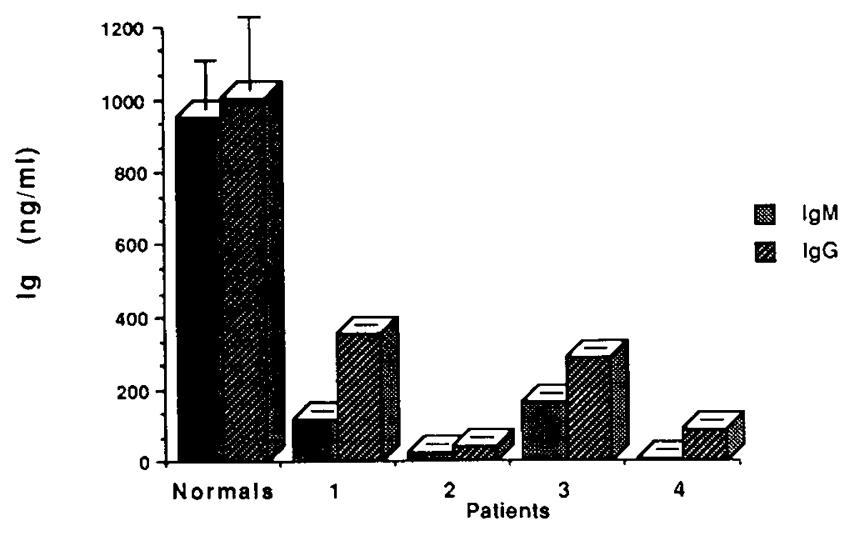

Fig. 2. Effect of CVI T-cell supernatants on Ig production by normal B cells. T cells from CVI patients and normal donors are stimulated 48 $\mathrm{h}$ with PHA, then added to normal SAC-activated B cells. The ability of $\mathrm{T}$-cell supernatants to support B-cell maturation and differentiation is reflected in B-cell Ig production, as measured by ELISA.

indicates that the lymphokine production abnormality in this group of CVI patients is specific for the TCR-CD3 activation pathway and that other signaling pathways (e.g. the CD28 pathway) are intact. As such, it is reminiscent of an earlier finding made with whole T-cell populations in which costimulation with phorbol myristate acetate was able to normalize IL-2 production by PHA-stimulated T cells (16).

Overall, these studies show rather unequivocally that a subgroup of CVI patients has a partial, but nonetheless definite, lymphokine production defect. This defect is unlikely to be one involving a global cell signaling abnormality inasmuch as cells can be induced to undergo normal proliferative responses by a variety of stimuli. More likely the defect is "downstream" of the signaling process, possibly at the level of the processes involved in the initiation of lymphokine gene transcription. In this regard, the defect may involve the elaboration of certain DNA binding factors that interact with particular regulatory (enhancer) regions located $5^{\prime}$ to lymphokine genes. This possibility would provide an explanation for the fact that IFN- $\gamma$ production is intact, because the DNA factors necessary for IFN- $\gamma$ mRNA production are not coextensive with those necessary for IL-2 mRNA production. Along these lines, the normal response of patient cells to anti-CD28 is explainable in that the IL-2 gene has an enhancer region that relates to $\mathrm{CD} 28$ signaling independently of enhancer regions relating to $\mathrm{CD} 3$ signaling (17).

\section{PATIENTS WITH ABNORMAL T-CELL PHENOTYPES: "CD8 $8^{\text {hi }}$}

In subsequent studies, we investigated the immunologic defect in a second group of patients with CVI, those with abnormal Tcell phenotypes. This group of patients constitutes a quarter to a third of all CVI patients and is marked by the presence of an elevated number of CD8+ T cells and a low CD4/CD8 T-cell ratio (18). In addition, the $\mathrm{CD} 8+\mathrm{T}$-cell population in this patient group usually contained increased numbers of HLA-DR+ and CD57+ T cells. The latter marker, CD57 (Leu 7), is one that has previously been found to be increased on $\mathrm{CD} 8+\mathrm{T}$ cells of patients with persistent viral infections (e.g. cytomegalovirus and human immunodeficiency virus infection), and CD8+, CD57+ $T$ cells have been shown to act as efficient cytotoxic $T$ cells in "redirected" (anti-CD3- or PHA-mediated) cytotoxicity assays (19-21).

In our studies of these $\mathrm{CD} 8^{\text {hi }}$ CVI patients, we first established that they were indeed different from those CVI patients with normal T-cell phenotypes with regard to lymphokine secretion. Accordingly, we determined the capacity of highly purified $\mathrm{CD} 4+\mathrm{T}$ cells from a CD8 ${ }^{\text {hi }}$ patient to produce IL-2 and IFN- $\gamma$ when stimulated by PHA. We found that CD4+ T cells from 
CD8 ${ }^{\text {hi }}$ patients produced IL-2 in a normal fashion, whereas CD4+ T cells from CVI patients with normal T-cell phenotypes (studied in parallel) produced reduced amounts of IL-2.

We then turned our attention to the $\mathrm{CD}^{\text {hi }}{ }^{\text {patients' }} \mathrm{CD} 8+\mathrm{T}$ cell population and determined the capacity of highly purified $\mathrm{CD} 8+\mathrm{T}$ cells to produce various lymphokines. When subjected to stimulation with anti-CD3/phorbol myristate acetate (a maximum $T$-cell stimulus), patient CD8 $+T$ cells produced significantly reduced levels of IL-2 and significantly increased levels of IFN- $\gamma$ and IL-5 as compared to a normal control CD8+ T-cell population; in addition, CD8 + T-cell production of IL- 4 was also increased, but in this case, to a nonsignificant extent. Thus, although the $\mathrm{CD} 8+\mathrm{T}$ cells in $\mathrm{CD} 8^{\mathrm{hi}}$ patients are relatively unreactive to proliferative stimuli, they nevertheless produce increased amounts of certain lymphokines.

The data on CD8+ T-cell lymphokine production described above suggested that these T cells are highly differentiated "effector-type" $T$ cells. To explore this possibility, we measured the capacity of CD8 $+T$ cells to act as suppressor $T$ cells and cytotoxic $T$ cells. In initial studies directed at suppressor T-cell activity, we performed studies to determine the capacity of $\mathrm{CD} 8^{\text {hi }}$ patients' CD8 + T cells to affect Ig production by SAC-induced allogeneic tonsillar B cells. We found, somewhat to our surprise, that whereas $C D 8+T$ cells from $C D 8^{\text {hi }}$ patients had little effect on normal B cell IgM production, they had a pronounced and cell dose-dependent inhibitory effect on IgG production. Thus, these cells affect the differentiation of normal B cells in vitro, either at the level of the isotype switch differentiation or the level of terminal differentiation.

In additional studies, we investigated the cytotoxic capabilities of $\mathrm{CD} 8+\mathrm{T}$ cells from $\mathrm{CD} 8^{\text {hi }}$ patients and showed that such cells have a markedly increased capacity to mediate cytolytic function in "redirected" (anti-CD3-mediated) cytotoxicity reactions. This indicates that $\mathrm{CD} 8+\mathrm{T}$ cells are, in fact, cytolytic $\mathrm{T}$ cells even if we cannot yet identify the antigen or antigens toward which the cells are specifically directed.

Having established that CD $8+T$ cells in $C D 8^{\text {hi }}$ patients had both suppressor and cytolytic functions, we investigated the possible role of these cells in the patients' hypogammaglobulinemia. First, we determined the capacity of highly purified $B$ cells from $\mathrm{CD} 8^{\text {hi }}$ CVI patients to produce Ig under SAC stimulation in the presence of IL-2. The reasoning here was, if the $\mathrm{CD} 8+\mathrm{T}$ cells were exerting an inhibitory effect that accounted for the hypogammaglobulinemia of this form of CVI, patient $B$ cells cultured in the absence of patient $T$ cells should be able to produce Ig. We found that although all patients' B cells produced IgM under these conditions, the B cells of three of four patients produced markedly reduced amounts of IgG. The Ig production defect of these patients, therefore, could not be corrected by simply removing potentially suppressive $T$ cells. A fourth patient's B cells, on the other hand, did produce IgG in the absence of his $\mathrm{T}$ cells. This patient is of interest because he had normal serum IgM levels associated with reduced IgG levels; thus, in this case, there was a good correspondence between in vitro and in vivo findings and it was reasonable to postulate that his Ig deficiency was due to Ig class-specific immunosuppression. Second, we showed that although the CD8+ T cells were cytolytic they had little or no capacity to kill allogeneic Epstein-Barr virustransformed B-LCL cells and subnormal cytotoxicity against autologous B-LCL cells; thus, it is unlikely the CD8 $+\mathrm{T}$ cells of $\mathrm{CD} 8^{\mathrm{hi}}$ patients act to kill $\mathrm{B}$ cells in vivo.

\section{SUMMARY}

The above studies allow us to define two very different CVI patient populations. The first patient group is characterized by a normal $T$-cell phenotype and $T$ cells (CD4 $+T$ cells) that have a partial abnormality of lymphokine production. The significance of this T-cell abnormality to the patients' hypogammaglobulinemia is uncertain. On the one hand, it is possible that the abnormality is a primary factor in the accompanying B-cell defect and is capable of causing a subtle but critical block in B-cell development leading to in vivo and in vitro B-cell unresponsiveness. In this view, the function of patient $B$ cells in culture is not indicative of an intrinsic B-cell defect, but rather a developmental defect secondary to the demonstrable T-cell lymphokine production abnormality. On the other hand, it is also possible that the $\mathrm{T}$-cell defect is one that is independent of the B-cell defect and that the latter is a primary factor in disease pathogenesis. In this context, it is possible that this form of CVI is caused by a common intracellular defect that independently causes an abnormality of lymphokine production in T cells and of Ig production in $\mathrm{B}$ cells.

The second patient group, $\mathrm{CD} 8^{\mathrm{hi}} \mathrm{CVI}$, is characterized by an abnormal $T$-cell phenotype and CD $8+T$ cells that manifest abnormalities of proliferation and lymphokine production. In this case, we again cannot clearly establish a role for the $T$ cells in the causation of the accompanying B-cell abnormality, except in the occasional patient, although it remains possible that such a role exists. In this case, we are impressed with the fact that the patients manifest a T-cell profile that is similar to that found in persistent viral infection, and it is thus worth considering the possibility that this form of CVI is due to a subtle and chronic infection that is the proximal cause of the B-cell dysfunction. The development of $\mathrm{CD} 8+\mathrm{T}$ cells is then a secondary phenomenon and not the cause of the hypogammaglobulinemia.

Overall, the studies presented here provide a new way to organize CVI into more coherent pathophysiologic groups. In addition, the studies begin to provide a molecular explanation of the disease and suggest important leads as to the direction of future research.

\section{REFERENCES}

1. Asherson GL 1980 Diagnosis and Treatment of Immunodeficiency. Blackwell Scientific Publications, London, pp 37-60

2. Mayer L, Fu SM, Cunningham-Rundles C, Kunkel HG 1984 Polyclonal immunoglobulin secretion in patients with common variable immunodeficiency using monoclonal B cell differentiation factors. J Clin Invest 74:21152120

3. Ashman RF, Saxon A, Stevens RH 1980 Profile of multiple lymphocyte functional defects in acquired hypogammaglobulinemia, derived from in vitro cell recombination analysis. J Allergy Clin Immunol 65:242-256

4. Siegal FP, Siegal M, Good RA 1976 Suppression of B-cell differentiation by leukocytes from hypogammaglobulinemic patients. J Clin Invest 58:109122

5. Siegal FP, Siegal M, Good RA 1978 Role of helper, suppressor, and B-cell defects in the pathogenesis of hypogammaglobulinemia. $\mathrm{N}$ Engl $\mathrm{J}$ Med 299:172-178

6. Rodriguez MA, Bankhurst AD, Williams RC 1983 Characterization of the suppressor activity in lymphocytes from patients with common variable hypogammaglobulinemia: evidence for an associated primary B-cell defect. Clin Immunol Immunopathol 29:35-50

7. Sneller MC, Strober W 1990 Abnormalities of lymphokine gene expression in patients with common variable immunodeficiency. J Immunol 144:37623769

8. Spickett GP, Webster ADB, Farrant J 1990 Cellular abnormalities in common variable immunodeficiency. Immunodefic Rev 2:199-219

9. Kruger G, Welte K, Ciobanu N, Cunningham-Rundles C, Ralph P, Venuta S, Feldman S, Koziner B, Wang CY, Moore MAS, Mertelmann R 1984 Interleukin-2 correction of defective in vitro $\mathrm{T}$-cell mitogenesis in patients with common variable immunodeficiency. J Clin Immunol 4:295-303

10. Jeong G, Ralph P, Nakoinz I, Saiki O, Cunningham-Rundles C 1985 Rescue of IgM, IgG and IgA production in common variable immunodeficiency by $\mathrm{T}$ cell-independent stimulation with Epstein-Barr virus. J Clin Immunol 5:122-129

11. Paganelli RM, Capobianchi R, Ensoli B, Gofizi GP, Facchini J, Diazani F, Auti F 1988 Evidence that the defective gamma interferon production in patients with primary immunodeficiencies is due to intrinsic incompetence of lymphocytes. Clin Exp Immunol 72:124-129

12. Pastorelli G, Roncarolo MG, Touraine JL, Peronne G, Tovo PA, DeVries JE 1989 Peripheral blood lymphocytes of patients with common variable immunodeficiency produce reduced levels of interleukin- 4 , interleukin- 2 and interferon- $\gamma$, but proliferate normally upon activation with mitogens. Clin Exp Immunol 78:334-340

13. Sanders ME, Makgoba MW, Shaw S 1988 Human naive and memory T-cells: reinterpretion of helper-inducer and suppressor-inducer subsets. Immunol Today 9:195-199

14. Grabstein K, Dower S, Gillis S, Urdal D, Larsen A 1986 Expression of 
interleukin-2, interferon- $\gamma$ and the IL-2 receptor by human peripheral blood lymphocytes. J Immunol 136:4503-4508

15. Kronke M, Leonard WJ, Depper JM, Greene WC 1985 Sequential expression of genes involved in human $T$ lymphocyte growth and differentiation. $J$ Exp Med 161:1593-1598

16. Fielder W, Sykora KW, Welte K, Kolitz JE, Cunningham-Rundles C, Holloway K, Miller GA, Souza L, Mertelsmann R 1987 T-cell activation defect in common variable immunodeficiency: restoration by phorbol myristate acetate or allogeneic macrophages. Clin Immunol Immunopathol 44:206-218

17. Fraser JD, Irving BA, Crabtree GR, Weiss A 1991 Regulation of interleukin-2 gene enhancer activity by the $T$ cell accessory molecule CD28. Science 251:313-316

18. Wright JJ, Wagner DK, Blaese M, Hagengruber C, Waldman TA, Fleisher TA 1990 Characterization of common variable immunodeficiency: identification of patients with distinctive immunophenotypic and clinical features. Blood 76:2046-2051

19. Carney WP, lacoviello V, Hirsch MS 1983 Functional properties of T lymphocytes and their subsets in cytomegalovirus mononucleosis. J Immunol 130:390-393

20. Gupta S 1986 Abnormality of Leu $2+7+$ cells in acquired immune deficiency syndrome (AIDS), AIDS-related complex, and asymptomatic homosexuals. J Clin Immunol 6:502-509

21. Ruthlein J, James SP, Strober W 1988 Role of CD2 in activation and cytotoxic function of CD8/Leu-7 positive T cells. J Immunol 141:3791-3797

\section{FLOOR DISCUSSION}

Dr. Winkelstein: I am particularly interested in the CD8/ CD57 population and I would like to ask you a number of questions about that. I think this is an extraordinarily interesting subpopulation of cells. First of all, you mentioned that they are "cytotoxic cells." As you know, there is a T-gamma lymphoproliferative disease that is characterized by an increase in CD8/ CD57 population. These are not cytotoxic T cells, at least in the majority of the cases. Do you know for a fact that the cells in the patients you described are cytotoxic, or is this just because they carry an NK (natural killer) cell antigen?

Dr. Strober: I am glad you asked that question because Dr. Jaffe in our laboratory has just completed a series of experiments in which he looked at redirected cytotoxicity using anti-CD3 to direct $\mathrm{CD} 8^{\text {hi }} \mathrm{CD} 8+\mathrm{T}$ cells to particular targets. He was able to show that $\mathrm{CD} 8+\mathrm{T}$ cells in the $\mathrm{CD} 8^{\mathrm{hi}}$ patients have very high cytotoxic capacity for nonspecific targets. Thus, at least in redirected cytotoxicity, the $\mathrm{CD} 8+\mathrm{T}$ cells are very definitely cytotoxic cells.

Dr. Winkelstein: I believe they have been shown to be cytotoxic when stimulated with $\mathrm{CD} 3$, but do they have spontaneous cytotoxicity?

Dr. Strober: In a series of studies in which we expanded the patient's B cells with EBV (Epstein-Barr virus) and then looked at the capacity of the CD8 cells to kill the patient's own EBVtransformed B cells, we did not find that the patient's $T$ cells were more cytotoxic than normal. However, we are not sure that we are stimulating these cells in the right way.

Dr. Winkelstein: In T-gamma lymphoproliferative disease, $20 \%$ of the patients are hypogammaglobulinemic, which may go along with your thesis that they are directly suppressive. Have you looked to see whether the cells in the CVI patients are clonal? The reason I suggest this is that a third of the patients with Felty's syndrome have an expansion of this same population of cells, which appears to be a clonal expansion of CD57 cells. I wondered whether you see any clonality in CVI patients with this increased population.

Dr. Strober: We are very interested in this question and have looked at these patients for clonality using Southern blot hybridization to see whether we could see a specific band. We have data on this, but I prefer not to go into detail at this time.

Dr. Winkelstein: Finally, you mentioned that this cell population is expanded in the AIDS patients, which I think is a very interesting phenomenon in itself, but I think it is important to recognize that although the AIDS patients are hypergammaglobulinemic they often respond very poorly to primary antigen stimulation. One wonders whether these cells could play a role in patients with AIDS who do not respond, for example, to pneumococcal vaccines.
Dr. Strober: That is very definitely a possibility.

Dr. Gelfand: In your first group of patients, the amelioration of the defect with anti-CD28 antibody and phorbol esters suggests that maybe you are obtaining stabilization of the message. It has been suggested that anti-CD28 and phorbols do this. Have you looked at message stability as opposed to decreased transcription?

Dr. Strober: No, we have not. Those are very difficult experiments. But I will say this: The concept of Carl June and his coworkers-that CD8 leads to increased IL-2 through stabilization of message-is being rethought now. Most people currently believe that the mechanism of anti-CD28 effect is an increase in IL-2 production as well as a stabilization message.

Dr. Gelfand: In the second group of patients, there is now a suggestive genetic association of CVI with particular completypes and haplotypes. How do you reconcile what you are describing in this group of patients with this possible genetic association? Have you looked at whether these patients do have a common phenotype?

Dr. Strober: Well, I think one thing that could be done immediately is to look to see if these two different types of patients fit into one completype or another. I really do not have the answer to your question, and neither does anyone else. Nobody really knows how a gene in the MHC class III, perhaps related to a complement protein, would cause individuals to be susceptible to this kind of disease. This disease is likely to be multigenetic, and we have environmental factors operating on a number of different genes.

Dr. Levinson: Didn't someone show that some of the complement factors or receptors are involved in down-regulating $\mathrm{T}$-cell activation? I think there is a fair amount of data on that in the literature, although I do not remember whether it is C2.

Dr. Strober: The fact is nobody knows what gene in the MHC class III region is, in fact, abnormal. It is simply not known whether it is one of the complement genes or a related gene. We just have to have more information on this before we can speculate.

Dr. Frank: I want to ask you a different kind of question. Most of the patients that have CVI have about $200-250 \mathrm{mg} / \mathrm{dL}$ of IgG. Is there anything that suggests that some B-cell clones get through this process, escape this intrinsic defect? Is anything known about the qualitative features of the immunoglobulin in these patients with CVI who have serum levels of 200 or so $\mathrm{mg} /$ $\mathrm{dL}$ ?

Dr. Strober: The antibodies are not oligoclonal. That fits with the general point that I am making here, that we have a partial defect of lymphokine production. The latter may lead to some differentiation and maturation of $B$ cells.

Dr. Levinson: Fred Shaeffer, who is in the audience, did some of the MHC class III studies on CVI and IgA deficiency with Max Cooper. Perhaps he would like to comment on this issue.

Dr. Shaeffer: Max and I looked at about 35 patients, consisting mostly of selective IgA deficiency and heterogenous phenotypes of CVI. We did not look at CD8/57 double-positive demarcations, but as part of the work we did look at the CD4/CD8 ratios. The majority of the patients had decreased ratios. Out of this specific population of patients, three extended MHC haplotypes, from class I through class II and III, were manifested in $80 \%$ of the patients. With regard to the other question about the role of the genes in MHC class III, there are over $60 \mathrm{MHC}$ class III genes. Thirty-five of them are unknown. So I think the jury is still out as to whether there is a direct or indirect effect of these genes. And as Dr. Strober stated, it is a polygenic disorder in which environmental factors play a role. To give credit to Dr. Hans Ochs and his group, they were one of the first groups to show, at least in guinea pig models, that MHC class III complement genes have a very direct effect on secondary antibody production and isotype switching from $\operatorname{IgM}$ to $\operatorname{IgG}$ for specific antigens. This was done in the early 1970 s.

Dr. Berger: In the first group of patients who have decreased interferon production over time, do those patients have skin test 
anergy or are there clinical differences that allow you to distinguish them?

Dr. Strober: No. Again, we have to do better studies than we have so far. I really do not want to be definitive about this question. In Tom Fleischer's studies, he found more anergy among the $\mathrm{CD} 8^{\text {hi }}$ patients, the second group of patients. Because we are looking at a partial defect, there may be enough lymphokine production to give normal cell-mediated immunity in most cases. It is going to take a lot more time to bring this dichotomy into line with possible in vivo immune defects.

Dr. Sorensen: You induced normal immunoglobulin synthesis in your first group of patients. I wonder if you also could induce normal immunoglobulin synthesis in vitro by adding IL-2 directly to $\mathrm{B}$ cells or to the patient's $\mathrm{T}$ cells?

Dr. Strober: The point I was making is that we could not stimulate normal $T$ cells with anti-CD3 and get the patients' $B$ cells to work, and by working I mean producing IgG. We could not get them to work by adding IL-2 or any other maneuver. Lloyd Mayer showed that T-cell supernatants from various kinds of hybridoma lines and other T-cell lines did stimulate the patient's B cells to make IgM, at least in some cases, but they did not make IgG. That is very critical because many times one can show that CVI patients will make IgM in vitro, in a variety of situations, but they will not make $\mathrm{IgG}$, and that is very critical to define the defect.

Dr. Wedgwood: The differentiation that you make is fascinating, but I wonder whether the two types had any clinical distinguishing marks? To go a little further, obviously the major problem in CVI is antibody production. As you know, antibody production can be dissected far more rigorously in vivo than by looking at just immunoglobulin levels. Many years ago, our group showed that we could demonstrate subgroups in CVI using bacteriophage. Some, perhaps most, patients made IgM antibody, but they did not seem to have memory or recall or amplification. Some had an IgM memory and amplification and others made some IgG. Going back to the early papers on complement, Hans Ochs was able to show very nicely that whether you made the IgM switch to IgG depended on complement, but it also depended on whether there was enough antigen to push it all the way forward. If so, you could get the IgM response to switch to $\mathrm{IgG}$ production. How did you evaluate these patients for their ability to make antibody in vivo? Did you look at the process and the timing of the switch from IgM to IgG in response to various stimuli?

Dr. Strober: No. We have not done that. I think it would be very interesting to do that now in these two more clearly defined patient groups. I take your point, and I am certainly aware of your studies with $\Phi X 174$.

Dr. Boxer: Did any of these patients in the second group with the TH suppressors have secondary cytopenias (like neutropenia, anemia, thrombocytopenia)? And was that accompanied by antiblood cell antibodies?

Dr. Strober: No, not in this particular group of patients. We have seen patients with hypogammaglobulinemia and cytopenias, presumably due to antibodies to red cells or thrombocytes. But this particular group of patients did not have that.

Dr. Schwartz: I am very curious to know whether you did the extension of your mixing experiments, when you used the CD8 cells and the normal SAC-stimulated cells, by using supernates or do you have evidence of any soluble activity that may come from that CD8 population you referred to?

Dr. Strober: That is a good question. We want to do that experiment and simply throw in antibody to IFN- $\gamma$, but we have not done it yet. I think it would be very important to show that the suppressor cell phenomenon may be due to one of the welldescribed lymphokines or cytokines. Is it simply the combination of very low IL-2 and very high IFN- $\gamma$ that gives rise to suppression? We really need to do a lot more in that area. 